\title{
Patterns in island endemic forest-dependent bird research: the Caribbean as a case-study
}

\author{
Eleanor S. Devenish-Nelson ${ }^{1,2}$ (D) . Douglas Weidemann ${ }^{3}$. Jason Townsend ${ }^{4}$. \\ Howard P. Nelson ${ }^{1}$
}

Received: 25 October 2018 / Revised: 19 March 2019 / Accepted: 26 April 2019 / Published online: 4 May 2019

(c) The Author(s) 2019

\begin{abstract}
Unequal patterns in research effort can result in inaccurate assessments of species extinction risk or ineffective management. A group of notable conservation concern are tropical island endemic birds, many of which are also forest-dependent, which increases their vulnerability to extinction. Yet, island bird species have received limited research attention compared to their continental congeners, despite this taxon being globally regarded as well-studied. We used the insular Caribbean, a globally important endemism hotspot with high rates of deforestation, to explore research bias of island and regional endemic forest-dependent birds. A review of the published literature $(n=992)$ found no significant increase in the number of studies over the search period. Research effort was significantly higher among species with threatened status, long generation time, wide habitat breadth and low to intermediate elevational distributions. Among family groups, the Psittacidae received the highest research effort, while the Cuculidae were the most underrepresented family (30-fold higher and six-fold less than expected, respectively). We found geographic biases in effort, with Jamaica having six-fold less and Puerto Rico eight times more research than expected for their level of endemism. These patterns likely reflect individual interests and limited capacity and funding, typical of Small Island Developing States. With over $50 \%$ of species in this review having declining population trends, we recommend prioritizing research that emphasises conservation- and management-relevant data across underrepresented families and islands, by fostering greater collaboration between researchers, practitioners and the existing local amateur ornithological community.
\end{abstract}

Keywords Biodiversity hotspot - Biogeography - Caribbean · Extinction risk - Islands . IUCN Red List · Life history · Phylogeny

Communicated by Peter J. T. White.

This article belongs to the Topical Collection: Forest and plantation biodiversity.

Electronic supplementary material The online version of this article (https://doi.org/10.1007/s1053 1-019-01768-x) contains supplementary material, which is available to authorized users.

Eleanor S. Devenish-Nelson

ellie.devenish@ed.ac.uk

Extended author information available on the last page of the article 


\section{Introduction}

Evaluating conservation and management effectiveness requires robust data (Sutherland et al. 2004). With global landscape change increasingly leading to declines in even common species (Inger et al. 2015; Julliard et al. 2004) and the potential for climate change to exacerbate these declines (Şekercioğlu et al. 2008), it is important that there are robust baseline data on which to build assessments of species-specific responses to threats, extinction risk and the effectiveness of conservation and management actions. Yet, for many taxa we lack such fundamental ecological data (Clark and May 2002; Cronin et al. 2014; Lawler et al. 2006). Identifying gaps in research effort is a valuable step in addressing the potential mismatch between scientific research and conservation action (de Lima et al. 2011). Research effort is influenced by factors such as extinction risk, phylogeny, life history, donor funding priorities, and country income (de Lima et al. 2011; Ducatez and Lefebvre 2014; Freile et al. 2014), which means that for some species disproportionately less is known about their ecology or data relevant to conservation problems are not available. Examining how these potential biases in research effort are manifested provides a foundation on which to explore what data are actually collected versus what is required for species conservation. Documenting patterns in research bias is therefore an important step to assess potential gaps between conservation data needs and ecological research.

Globally, 60\% of the world's bird species are forest-dependent (Buchanan et al. 2011). Forest-dependent bird species rely on habitats that are increasingly vulnerable to land degradation and climate change (Bird et al. 2012; Buchanan et al. 2011; Deikumah et al. 2015). Indeed, extinction risk increases with the level of a species' forest-dependency and, this is particularly pronounced in the tropics (Newbold et al. 2013). Further, most threatened island endemic bird species are forest-dependent (IUCN 2017; Johnson and Stattersfield 1990) and compared to their continental congeners, such island endemic birds often face a higher extinction risk (Duncan and Blackburn 2007; Fordham and Brook 2010; Frankham 1998; Johnson and Stattersfield 1990). Despite birds being arguably one of the most studied taxonomic groups (Clark and May 2002; Cronin et al. 2014) and islands being of biogeographic significance (Hedges 2001), there remains a paucity of research of tropical island birds (Brooks et al. 2002; de Lima et al. 2011).

The Caribbean is among the most diverse of the insular biodiversity hotspots (Brooks et al. 2002), with $80 \%$ of its endemic bird species being forest-dependent (BirdsCaribbean 2019; IUCN 2018), well above the global average. This makes the Caribbean an ideal case study for assessing the status and quality of current ecological data for this extinction-prone group of birds. Historically, the Caribbean has suffered a significant amount of avian extinctions as exemplified by the loss of about $55 \%$ of its endemic parrots since the 1400 s and currently, many bird populations continue to experience substantial population declines (Wunderle 2008). Today, almost a third of Caribbean endemic forest-dependent bird species are threatened with extinction, due largely to habitat loss, invasive species and overexploitation (IUCN 2017), while simultaneously, many of the region's species of least concern are also experiencing population declines (e.g. Faaborg et al. 1997; Lloyd et al. 2016). Of all biodiversity hotspots, this region is also predicted to lose the highest number of endemic plant and vertebrate species due to future habitat loss (Brooks et al. 2002) and climate change impacts (Bellard et al. 2014). Caribbean forest habitats are invaluable for the global conservation of these threatened bird species (Buchanan et al. 2011). Yet, this biodiversity hotspot has less than $30 \%$ forest cover across the entire region (Gillespie et al. 2012), due to the cumulative impact of the legacy of colonial history, restricted land mass, 
high human population density and natural disasters (Holdschlag and Ratter 2013; Lugo et al. 2012b; Portillo-Quintero and Sánchez-Azofeifa 2010; Wiley and Wunderle 1993). While recent trends indicate abandoned agricultural lands on many islands in the region are reverting to forest, this recovery in cover masks a shift towards novel species communities (Lugo et al. 2012a), in which the response of many native species to these altered systems remains uncertain (Lugo et al. 2012a).

The future conservation of forest-dependent bird species in the Caribbean requires at the very least a basic understanding of their distribution and ecology. Despite their value as national and regional icons (Wunderle 2008), and their importance for ecotourism (Orgaz and López 2015), ecosystem services (Johnson et al. 2010) and as indicators of forest degradation (Davis 2017), there remain many gaps in our understanding of these taxa (Nelson et al. 2017). To date, the focus of avian research in the Caribbean has been largely on migratory bird species, leaving a data gap for resident species (Latta 2012; Tossas 2004), which make up approximately $70 \%$ of the region's approximately 450 breeding and regularly visiting avian species (BirdsCaribbean 2019). This paucity of data limits our ability to make appropriate conservation assessments and management decisions for these island species, further increasing their vulnerability to extinction.

To date, research effort, data biases and gaps for forest-dependent endemic bird species in the Caribbean have not been fully quantified. This study, part of a wider assessment (see Devenish-Nelson et al. 2017), reviews the published primary literature to evaluate the current state of research effort for Caribbean endemic, forest-dependent birds. Specifically, this review asks (i) what is the current status of research effort for Caribbean endemic forest-dependent birds? (ii) what are the subject trends in existing research effort? (iii) does research effort differ between threatened species and non-threatened species? and (iv) is there a bias in research effort associated with endemism, biogeography, phylogeny, ecology or life history?

\section{Methods}

In this analysis, we defined the Caribbean as the islands within the Caribbean Sea (Hedges 2001), including the islands of the Bahamas, Trinidad and Tobago and Bermuda, as well as the Caribbean islands of South and Central America, such as those on the Caribbean coast of Nicaragua and Colombia (Fig. 1). The nomenclature for Caribbean forest-dependent endemic bird species included in this review followed the AOU 7th Edition Checklist (American Ornithologists' Union [AOU] 1998) and subsequent supplements (http://check list.aou.org/). We classified forest-dependency according to the Birdlife Data Zone (Birdlife International 2016), which uses the IUCN Red List habitat classification system (IUCN 2017) to assign species as low, medium, high or not forest-dependent. Only species classified as medium and high forest-dependency were included in these analyses. Extinction risk and population trend for all species in this analysis were assigned according to the IUCN Red List (IUCN 2017). Since all Caribbean bird extinctions occurred prior to the first comprehensive IUCN bird assessment in 1988 (IUCN 2017), extinct species and species extinct in the wild were excluded from all analyses. Using these criteria, a total of 136 species were included in our study as forest-dependent, and these consisted of 96 resident island endemics and 40 regional (near) endemics (shared by neighbouring islands; Miller and Miller 2001). For ease, the use of 'endemic' throughout the paper refers to both these island and regional endemic species. 


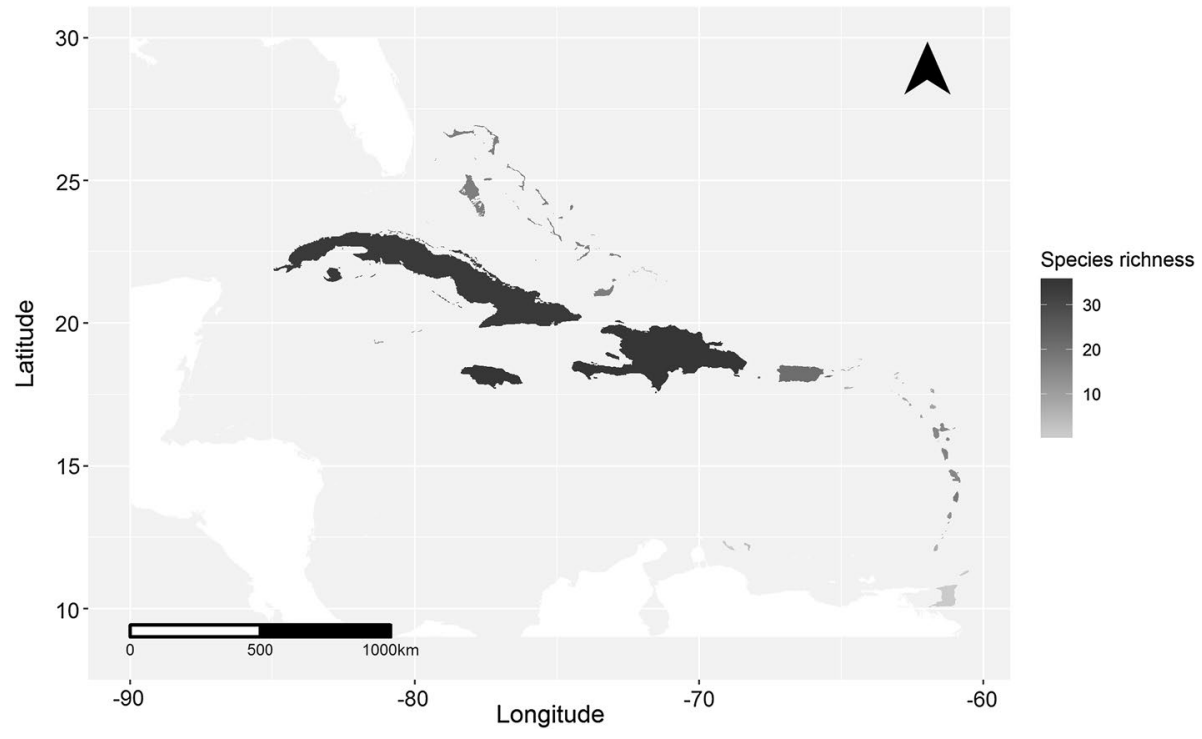

Fig. 1 Map showing the species richness of forest-dependent endemic and regional endemic species for the insular Caribbean islands included in this study (excepting Bermuda, which we have not included in this figure since it has no forest-dependent endemic species)

\section{Research effort}

To quantify research effort, we conducted a systematic review of Web of Science (WoS) between 9th June and 20th July 2016. The exhaustive coverage of academic journals by WoS means it is widely used as an indicator of global research effort (de Lima et al. 2011). In this review the WoS 'All Databases' search option was used (comprising 11 Citation Indices under the institutional subscription, including the Web of Science Core Collection, Zoological Record and BIOSIS Citation Index). Peer-reviewed publications for each species were extracted from 1988 (the year of the first fully comprehensive IUCN Red List bird assessment) to 2016. We performed searches using full scientific names and all recognised taxonomic synonyms. We reviewed titles and abstracts of all papers to assess the relevance for inclusion in the analyses. We defined the geographic location of a study according to the island to which the species is endemic, and thus included independent nations (e.g. Bahamas), dependent territories (e.g. Montserrat), shared island nations (e.g. Hispaniola) or Caribbean islands considered politically part of a continental country (e.g. San Andres). Studies pertaining to near endemics were categorised as 'regional'. For each study, we recorded the year of publication, and used linear regression to test for temporal change in the number of publications over the review period.

\section{Subject bias}

To determine whether research effort is biased towards specific subject areas, following similar methods (Bautista and Pantoja 2000; Freile et al. 2014; Mugica et al. 2012), we assigned studies to 11 research categories (Table 1), allocating multiple categories per 


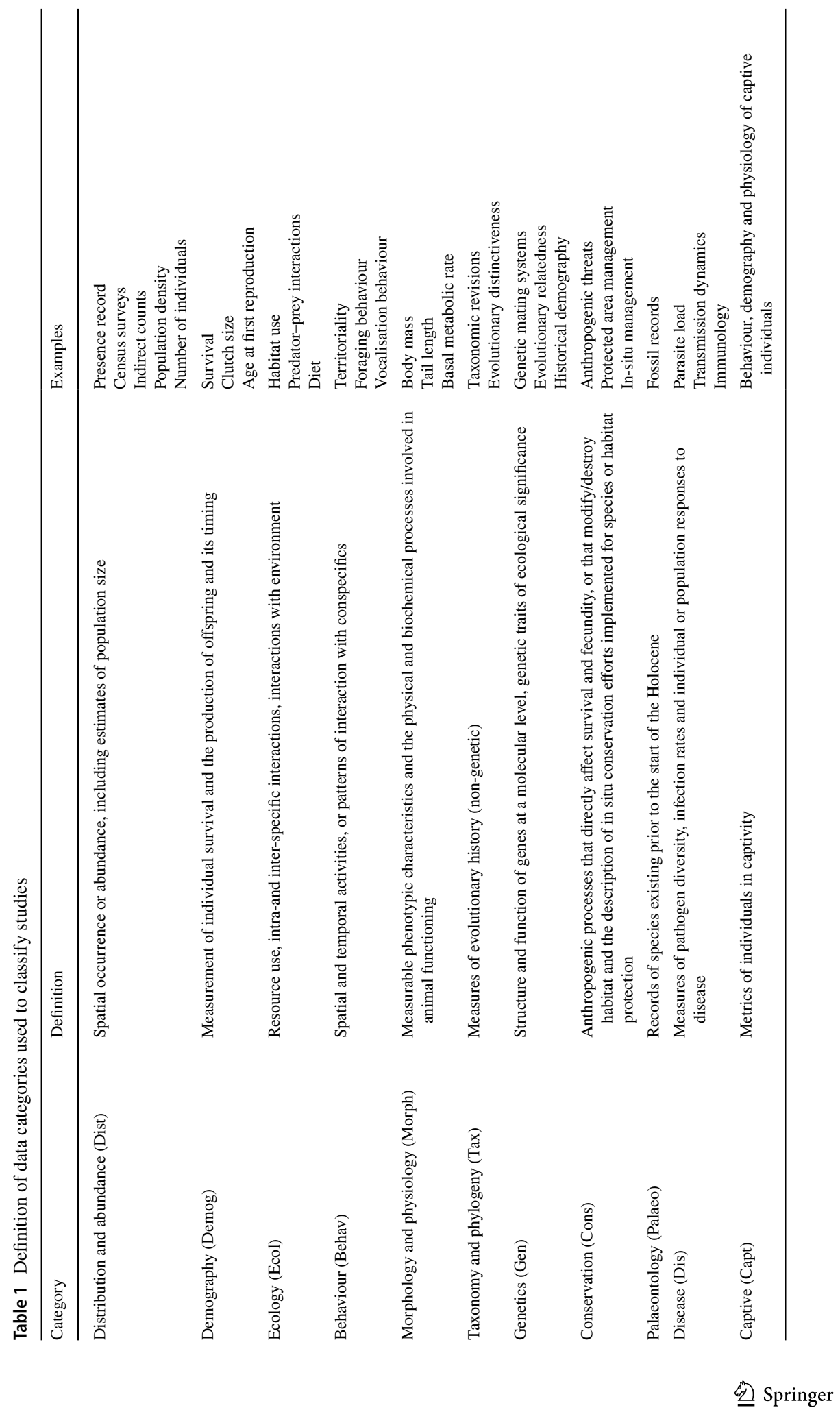


study if appropriate. Although this classification was subjective, this approach allowed a broad overview of the range of topics of the published research. We assessed the difference among subject categories in research effort per species using a Kruskal-Wallis test and a post hoc Mann-Whitney $\mathrm{U}$ test. We calculated the effect size, $r$, for each pairwise comparison ( $r=$ Mann-Whitney $Z / \sqrt{ } n$ ) to indicate the strength of the relationship between two subject categories. We also conducted a network analysis to determine the relationship between categories, based on the number of links between pairs of categories, using the R packages 'igraph' (Csardi 2013) and 'qgraph' (Epskamp et al. 2012). We used linear regression to investigate whether the number of papers in each subject category had changed over time. Due to the small number of species in some IUCN Red List categories, we pooled species into a binomial index of threatened and non-threatened categories in these analyses. This was done using two approaches: first, we included critically endangered CR, endangered EN, vulnerable VU and near threatened NT Red List species in the threatened category, and categorized least concern LC species as non-threatened. Second, we moved the near threatened NT Red List species to the non-threatened category. This was done to examine the impact of the near-threatened group on the binomial categorization we were examining, given the variability in the way the near-threatened group is treated in the literature (e.g. Arregoitia et al. 2013; Ducatez and Lefebvre 2014; Murray et al. 2015; Roberts et al. 2016). We used a Wilcoxon test to determine the difference in the number of papers per species in each subject category between threatened and non-threatened species in the resulting two binomial categorization approaches above.

\section{Extinction risk bias}

The degree of extinction risk can influence the research effort applied to different species (de Lima et al. 2011). We used a Wilcoxon test to determine whether there was a significant difference in research effort between threatened and non-threatened species and Pielou's evenness index to measure equitability in effort within each category. Using a Kruskal-Wallis test we assessed differences across population trends ('increasing', 'stable' and 'decreasing'; those with an 'unknown' trend were removed from this analysis). We also used a Kruskal-Wallis test to investigate whether there was a relationship between research effort and those species undergoing any IUCN Red List change over the review period (1988-2016). We followed the IUCN guidelines (IUCN 2017) for determining genuine Red List change; due to small sample sizes for this analysis we did not consider the magnitude of the change, assigning species to one of three change categories (genuine positive, genuine negative, or no change).

Bias was determined among taxonomic groups and geographic location relative to threat status, since this can identify research needs in taxa or areas with a high proportion of threatened species (de Lima et al. 2011; Ducatez and Lefebvre 2014; Verde Arregoitia 2016). We calculated the expected number of studies for a given number of threatened species by both family and island. Here,

$$
f_{i}=\left(\frac{v_{i}}{V_{T o t}}\right) P_{T o t}
$$

where $f_{i}$ is the expected number of studies for family/island $i, v_{i}$ is the number of threatened species for $i, V_{T o t}$ is the total threatened species (area-adjusted for island size, estimated as total species/log $\left(\right.$ area $\left.\mathrm{km}^{2}\right)$ ) across all categories and $P_{T o t}$ is the total number of published 
studies (Verde Arregoitia 2016). Pearson residuals, $r$, were then calculated to determine the significance of the deviance between the observed and expected frequencies.

\section{Endemic species richness bias}

We repeated the above analysis to determine bias among taxonomic groups and geographic regions relative to endemism to identify research needs in taxa or areas with high endemic species richness of forest-dependent birds. To calculate the expected number of studies for a given endemic species richness per family or island, in Eq. 1, $v_{i}$ is species richness for $i$ and $V_{T o t}$ is the total species richness across all categories.

\section{Life history and phylogenetic bias}

Life history traits and phylogeny can be important predictors of research effort (Brooke et al. 2014; Ducatez and Lefebvre 2014). We used a phylogenetic generalized linear mixed model (PGLMM) (de Villemereuil and Nakagawa 2014) to determine associations between life history and ecological traits and research effort. Species with traits that make them prone to extinction are expected to be the subject of more studies, such as large bodied species, those with long generation lengths, low reproductive rates, small ranges or dietary or habitat specialists. Life history data on body weight and clutch size were collated from multiple sources (Bennett 1986; Cornell 2016; del Hoyo et al. 2016; Dunning 1992; Myhrvold et al. 2015; Raffaele et al. 2003), with estimates of these parameters averaged where multiple records were available. Generation length followed the IUCN Red List definition and was obtained from the BirdLife Data Zone (Birdlife International 2016). Given the importance of maximum elevation in driving extinction risk (White and Bennett 2015), we included this variable in the analysis, determined from various sources (Cornell 2016; IUCN 2017; White and Bennett 2015). We would expect species that are more easily observable to be subject to more research effort, such as widespread species or those using multiple habitat types. Therefore, extent of occurrence was defined as reported in the IUCN Red List (IUCN 2017) and habitat breadth, the number of distinct habitats used by a species, was collated from the range of habitat types listed for each species on the IUCN Red List (IUCN 2017). We tested all eight life history and ecological variables for collinearity; those with $r>0.7$ or a Variance Inflation Factor (VIF) $>5$ were excluded from the analyses; otherwise they were log transformed before inclusion in analyses.

Since phylogeny can be a confounding factor due to non-independence of species traits among related species (Purvis et al. 2005), we included phylogeny as a covariance matrix (Hadfield 2010). One thousand phylogenetic trees from the 'Hackett backbone' were downloaded from www.birdtree.org (Jetz et al. 2012) and a consensus tree was obtained using the R package 'ape' (Paradis et al. 2004). A single model including all predictor variables was implemented with the R package 'MCMCglmm', specifying a Poisson family (Hadfield 2010). Uninformative priors $(V=1, n u=0.002)$ (Hadfield 2010) allowed the model fit to be guided by the data. We ran five model chains with $1,000,000$ iterations with a burn-in of 10,000 samples and a thinning interval of 2500. Convergence was assessed by inspection of trace plots and Gelman-Rubin diagnostics with a threshold of 1.1, in the 'coda' package (Plummer et al. 2006). Phylogenetic signal, $\lambda$, was calculated as the ratio of VP/ $(\mathrm{VP}+\mathrm{VR})$, where VP is the variance explained by phylogeny and VR is the residual variance (de Villemereuil and Nakagawa 2014). 


\section{Results}

\section{Research effort summary}

The literature review yielded a total of 1259 peer-reviewed papers. Of these results, $9.61 \%$ were removed from all analyses as being 'not relevant', with species only mentioned in passing, such as relating to different geographic locations or in global reviews. Data files (e.g. Dryad data sets) published to accompany peer-reviewed journal articles $(11.60 \%$ of the total effort) were also excluded from further analysis to avoid double counting since subject categories of data files were represented by accompanying full papers on WoS. There was a mean of $7.29 \pm 11.14$ SD $(n=992)$ studies per species, with the majority of species $(91.24 \%, n=136)$ referenced at least once in the published literature (Appendix $\mathrm{S} 1)$. Over the search period there was no significant increase in research effort $(F=3.1$, $r^{2}=0.103$, d.f. $\left.=27, p=0.090\right)$.

\section{Subject bias}

The mean number of published studies per species was highest for the subject categories 'distribution and abundance' $(1.69 \pm 2.12, n=230)$, 'conservation' $(1.60 \pm 4.45, n=217)$, and 'ecology' $(1.40 \pm 2.01, n=190)$. There was a significant difference in the number of papers by category type (Kruskal-Wallis test $\chi^{2}=186.30$, d.f. $=10, p<0.001$ ). Significant differences from post hoc pairwise corrections between research effort across subject categories exist, although the effect size for many of these relationships was low to moderate (mean $r=0.29 \pm 0.15$, Appendix S2). When treating near-threatened species as non-threatened, research effort was significantly greater in threatened than non-threatened species for 'distribution and abundance' $(p=0.005)$, 'conservation' $(p<0.001)$ and 'captive' $(p=0.004)$ studies (Appendix S3a). The same pattern was repeated when near-threatened were included in the 'threatened' category, with movement of 'demography' to the class of studies that were significant among threatened species ( $p=0.004$, Appendix S3b). Network analysis showed 'conservation' studies had strong links with 'distribution and abundance' and 'ecology', while 'genetics' and 'taxonomy' studies were strongly related (Appendix S4), suggesting that these subjects were studied in conjunction with each other more often than the other categories. While most subject categories showed no significant change over time, increases in effort across 'genetic', 'captive' and 'taxonomy' studies and decreases in 'distribution and abundance' studies were significant over the search period (Fig. 2).

\section{Extinction risk and endemism biases}

Research effort was significantly higher in threatened compared to non-threatened species (Wilcoxon test $p=0.015$ ) when treating near-threatened species as non-threatened, but this difference became non-significant when treating near-threatened species as threatened $(p=0.108)$. For both treatments of near-threatened species, research was more evenly distributed across species that were non-threatened compared to those that were threatened (Pielou's evenness indexes: 0.64 and $0.49 ; 0.66$ and 0.51 , respectively). There was a significant difference in research effort across population trend categories $\left(\chi^{2}=7.457\right.$, d.f. $\left.=2, p=0.024\right)$, with 'increasing' species having significantly 


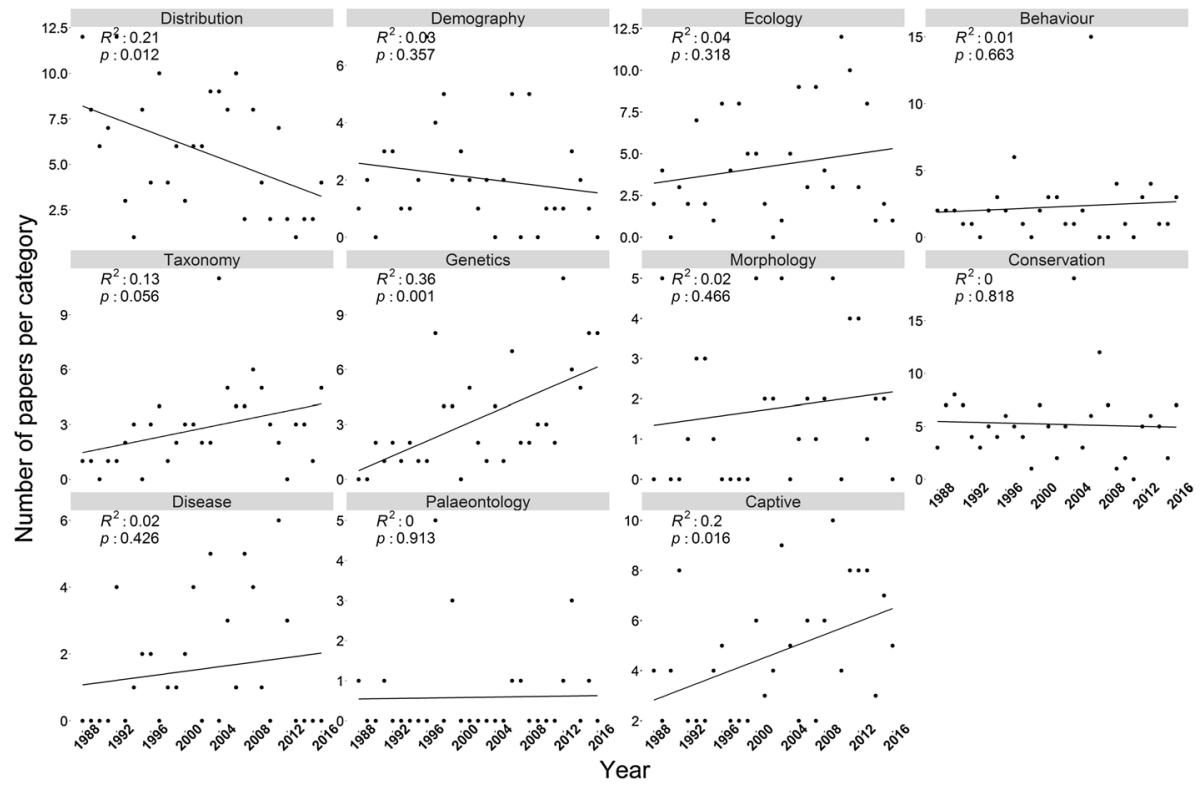

Fig. 2 Temporal change in research effort per subject categories for Caribbean forest-dependent endemic birds between 1988 and 2016. $R^{2}$ and $p$ values of linear regression are presented for each subject

more research than all other trend categories. Nine species were assigned a higher IUCN Red List category and four species were downlisted over the review period. There was no significant relationship between research effort and species undergoing IUCN Red List change $\left(\chi^{2}=1.05\right.$, d.f. $\left.=2, p=0.59\right)$.

Generally, research effort was lower than expected based on the number of endemic and threatened species in a given family, when treating near-threatened as non-threatened (Fig. 3a, b). The Cuculidae, Tyrannidae and Parulidae were nearly six-fold underrepresented in research effort for the number of endemic species (Fig. 3a), while the Columbidae and Parulidae had fivefold less research effort than expected for the number of threatened species in the family (Fig. 3b). Conversely, the Psittacidae had significantly higher than expected research effort given the level of both endemism (30 times higher) and extinction risk (16 times higher) for species within this family (Fig. 3a, b).Within the Psittacidae family $(n=10)$, three species contributed to over $60 \%$ of all publications ( $n=333$, Appendix S1). The results followed the same patterns when considering near-threatened as threatened (Appendix S5).

There was a similar pattern of low representation of research effort from many islands, given the amount of endemism and extinction risk and after adjusting for island area (Fig. 3c, d). Jamaica had substantially lower research effort than expected for both endemism (sixfold) and extinction risk of species (fourfold) on the island, while San Andres had over four times less for its species extinction risk (Fig. 3c, d). However, Dominica, Puerto Rico and Hispaniola had between four and six times more research than expected for their endemism, while Hispaniola and Puerto Rico had between five and nearly eight times more effort than expected for extinction risk (Fig. 3c, d). 
(a)

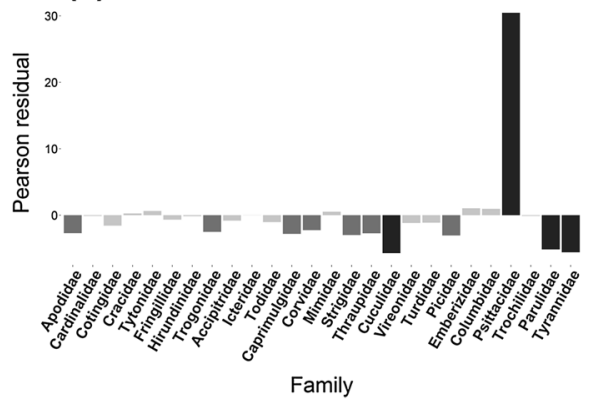

(c)

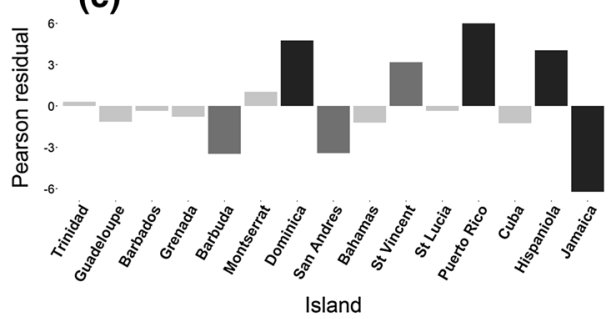

(b)

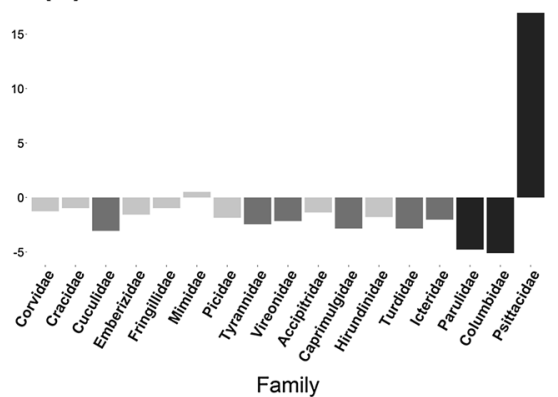

(d)

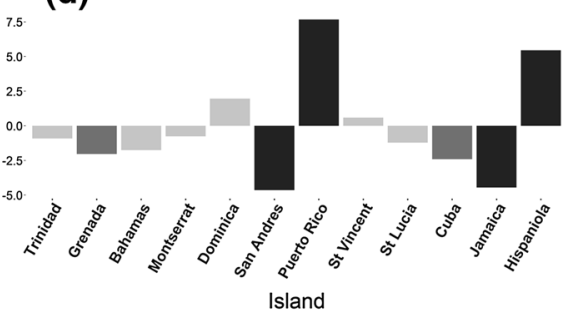

Significance $\square<0.01 \square<0.05 \square>0.05$

Fig. 3 Taxonomic (a, b) and geographic bias (c, d) in research effort for Caribbean forest-dependent endemic species richness $(\mathbf{a}, \mathbf{c})$ and threatened endemic species richness $(\mathbf{b}, \mathbf{d})$. Negative values indicate lower than expected research effort and positive values indicate higher than expected effort. Regional endemics are excluded from the geographic analysis. X-axes are ordered left to right by increasing number of species per group. See Appendix S1 for details of the species and observed studies. Pearson residuals above $|2|$ and $|4|$ are interpreted as being significant at the $\alpha=0.05$ and $\alpha=0.0001$ level, respectively

\section{Life history and phylogenetic bias}

PGLMM analysis was based on 121 species, after removing those species not recognised by BirdTree.org (e.g. due to recent taxonomic changes) and those with missing data. No collinearity was observed between the predictor variables. PGLMM chains were well mixed, Gelman-Rubin diagnostics indicated good convergence and the phylogenetic signal was low to moderate $(\lambda=0.17,95 \%$ CI $0.003-0.44)$. Results suggest an increase in research effort with longer generation length, wider habitat breadth and lower maximum elevation (Fig. 4, Appendix S6).

\section{Discussion}

\section{Current research effort}

This review is part of the first study (Devenish-Nelson et al. 2017), to our knowledge, that quantifies research effort for the forest-dependent endemic birds of the Caribbean, a group of specialist species that globally are highly vulnerable to extinction (Bregman et al. 2014; Carrara et al. 2015; Deikumah et al. 2015; Wunderle 2008). Nearly 1000 peer-reviewed 


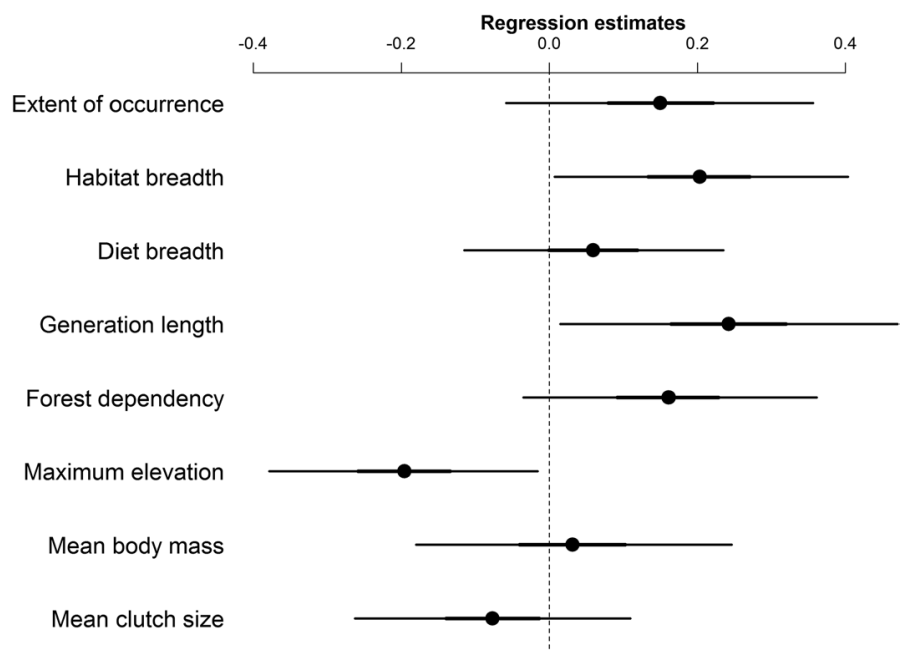

Fig. 4 Coefficient residuals from a PGLMM model of life history predictors of research effort on Caribbean forest endemic birds. Values that do not overlap with zero are significant. The vertical dotted line is positioned at zero and error bars denote $95 \%$ CIs

studies were identified since 1988 by our review; yet there was no significant increase over time in this research effort. This lack of a significant increase in research effort in all but a few Neotropical countries has been previously noted (Freile et al. 2014), and contrasts with an overall global increase in ornithological research (Ducatez and Lefebvre 2014). The Caribbean is not well represented in global ornithological literature (Brooks et al. 2008; Freile et al. 2014) and these results are consistent with the low ornithological research capacity in the region (Devenish-Nelson et al. 2017; Latta 2012; Levy 2008) and low research effort on restricted-range island bird species (de Lima et al. 2011). Historically, international funding for baseline ecological avian research in the Caribbean has been low compared to that for bird-related education and outreach, habitat conservation and capacity building (Castro et al. 2000). Despite the promise of research on migratory species providing increased information on resident birds and building capacity in the islands (Latta and Faaborg 2009), this has not broadly translated into a growing published literature for these species, based on our review. This is worrying since it indicates that these forestdependent endemic species are being systematically overlooked in the literature, compared to other groups of species. Encouragingly, work published since the review period of this study points toward a growing interest in this group (e.g. Rimmer et al. 2017; Townsend et al. 2018 and see the Journal of Caribbean Ornithology's 2017 Special Issue on the Status of Caribbean Forest Endemics). However, it is important to note that this is not the only metric of output of increased research capacity; see discussion below for the impact of the NGO community on avian conservation.

\section{What subjects are studied?}

Despite birds being a comparatively well-studied taxon, our study reveals substantial gaps and biases in research effort for endemic forest-dependent birds in the Caribbean. Research effort is driven by both local and global factors. Although it is hard to disentangle these 
drivers, logistical, technological, financial and capacity limitations, as well as individual research interests can explain much of the bias (Latta and Faaborg 2009; Levy 2008; Raffaele 2004). That 'distribution and abundance' data was a dominant category is consistent with patterns reported in the wider ecological literature for fundamental ecological studies of single species (Carmel et al. 2013), as also observed with the strong link with 'ecology' studies in this review. The emphasis on, and strong relationship between, 'conservation' and 'captive' studies in the literature for threatened species is unsurprising given the relevance to 'at risk' species (Conde et al. 2011; Lawler et al. 2006) and the need for evidence to inform conservation and management decision-making. The challenges of securing funding, managing the logistics of tropical research, and of maintaining the continuity of long-term studies (Lindenmayer et al. 2012), are also indicated in our results, such as in the limited demographic and disease-related data available for all Caribbean species.

Temporal changes in subject areas since 1988 reflect changing interests and perceived importance of topics as well as technological advances. The observed increase in 'genetic' studies is recorded more widely (Carmel et al. 2013) and is largely due to increasingly sophisticated and accessible techniques (DeSalle and Amato 2004). The growth of 'captive' studies was predicted in the 1990s, due to the recognition of the role of zoos for in situ conservation, as well as developments in technical research capacity (Ryder and Feistner 1995). Cataloguing species distributions and abundance has significantly decreased, as observed more generally in ornithology (Bautista and Pantoja 2000) and may reflect a growing emphasis in ecology on analytical science. However, successful citizen science initiatives, such as eBird (Sullivan et al. 2009), can now act as a repository for much of this distributional and abundance information.

\section{Which species are studied?}

Among-taxon biases are well documented in the published literature (McKenzie and Robertson 2015; Roberts et al. 2016). The underrepresentation of some families is possibly explained by behavioural, physical or ecological attributes, such as a secretive nature or low conspicuousness (e.g. the Tyrannidae, Diamond 1973; and Cuculidae, Hughes 1996), low densities or difficulties in identification (e.g. the Tyrannidae, Chaves et al. 2008; Tossas and Delannoy 2001). Positive research bias can also be driven by unique life history, which may account for some of the high research effort, such as social organisation (e.g. the cooperatively foraging Mimidae, Mortensen and Reed 2016). Charismatic species, notably the Psittacidae, popular in the pet trade, received significantly more research than expected, as previously noted in the Caribbean (Latta 2012), while less charismatic species may explain the low representation of some families in the literature (Cronin et al. 2014), such as the Columbidae. Within families, effort was not evenly distributed; for example, research in the Pscittacidae was skewed towards a small number of these extinction-prone and highly forest-dependent species. This pattern is also reflected globally with a small proportion of parrots being wellstudied (Marsden and Royle 2015). The contrast between research effort for resident and migratory species is exemplified by the underrepresentation of the resident Parulidae species in this review. Migratory warblers, such as Kirtland's warbler, Setophaga kirtlandii, are one of the best studied groups in the Caribbean (Latta 2012), benefiting from attention and funding from North American researchers and programmes such as Partners in Flight (Wunderle and Arendt 2017). Globally, migrant bird species are proportionally overrepresented in the literature, both due to the ecological importance 
of migratory behaviour and the geographic bias of research emanating from the global north (Ducatez and Lefebvre 2014). Encouragingly, resident endemic Parulidae have received recent attention from internationally-driven research on Caribbean migratory species (e.g. Lloyd et al. 2016; Townsend et al. 2013), although single-species ecological and demographic studies for this group remain limited.

Relationships of research effort with threat status vary across the literature depending on the subset of birds in question (Brooks et al. 2008; McKenzie and Robertson 2015; Murray et al. 2015; Roberts et al. 2016). Globally, studies have found higher effort among non-threatened species (Ducatez and Lefebvre 2014) but the converse was true for rangerestricted island species (de Lima et al. 2011). In the Caribbean, we found that research effort was only higher among threatened species if species currently classified as nearthreatened were included among the 'threatened' class. This analysis highlights the need for clarity in the way near-threatened species are considered when assessing the role of triage in conservation. Nonetheless, we noted that research was not equitable across threatened species in the Caribbean, highlighting the opposing vectors which rarity mediates on research effort. Specifically, rare species are more likely to be threatened (Manne and Pimm 2001) and are thus subject to greater research interest, especially with regards to their conservation, as observed in this study. Yet, rare species are also hard to study due to their low densities (Thompson 2013). In tropical forest habitats avian detectability can be substantially reduced (Anderson et al. 2015; Gale et al. 2009), leading to difficulties in obtaining the adequate sample sizes required for robust analyses.

Fewer studies have examined research effort in relation to population trend (but see McKenzie and Robertson 2015). Here, results suggested research was higher in those species with an increasing trend, but the small sample size cautions against drawing further conclusions. Similarly, although there was no relationship between research effort and change in IUCN Red List categories over time, sample sizes of species with either a genuine positive or negative change were low. It is encouraging that conservation efforts resulting in the recent downlisting of the Montserrat oriole, Icterus oberi (IUCN 2017), have been well documented in the published literature (e.g. Bambini et al. 2017; Oppel et al. 2014a; Oppel et al. 2014b), but further work is required to determine the relationship between such successful conservation actions and research and, whether high research effort leads to active species management or if species management drives research.

The moderate phylogenetic signal in the residual errors of the model suggests that research effort is not entirely random in relation to evolutionary history, but is in contrast to that previously reported for global research on birds, where a larger effect of phylogeny was found (Ducatez and Lefebvre 2014). Research effort in this review was also not randomly distributed among life history traits. The focus in these data on longer-lived species is in agreement with other studies (Ducatez and Lefebvre 2014). Longer-lived forestdependent bird species are particularly vulnerable to habitat degradation (Newbold et al. 2013). Among Caribbean birds, the focus on longer-lived species is driven in part by the high research effort on parrots, which are often both longer-lived and threatened species. The higher research effort found for low elevation species likely mirrors the challenges of the steep topography in the Caribbean (Lugo et al. 1981) and that globally, threats are higher for low elevation bird species (White and Bennett 2015). The high likelihood of research on species with a wide habitat breadth in this review also corresponds to other studies (Ducatez and Lefebvre 2014). While this appears contradictory with the relationship of ecological traits and extinction risk, it may reflect the fact that species found in multiple habitats have a higher likelihood of being observed, as demonstrated by the substantial contribution of distribution studies in this review. 


\section{Where are species studied?}

Some of the observed variation in research effort is likely due to the geographic distribution of charismatic species. For example, Dominica, Puerto Rico and Hispaniola all have endemic parrots (Wiley et al. 2004), a family subject to high research effort. Higher than expected effort may also reflect the presence of a focal conservation coordinator or 'species advocate', such as for many endemic species in Hispaniola and Puerto Rico (Wege and Anadon-Irizarry 2005) or the pride programmes for endemic parrots (Latta 2012; Wunderle 2008). However, high endemism and the presence of charismatic species does not translate into research effort for Jamaica (although see Davis 2017), which is of concern due to this island's particularly high conservation impact for forest-dependent birds (Buchanan et al. 2011). The substantial representation of Puerto Rican research effort is consistent with other studies (Freile et al. 2014; Latta 2012), reflecting the influence of established universities, US funding, and legal conservation mandates that lead to a structured research agenda (Latta 2012; Tossas 2004). The significantly lower than expected research output in Jamaica is surprising given the presence of several universities. However, this may be indicative that despite a recent increase in the number of universities in the English-speaking Caribbean, the culture of research remains weak (Lewis and Simmons 2010; Onyefulu and Ogunrinade 2005). Although much of the research on Caribbean forest-dependent endemic birds is driven by externally-based researchers (Devenish-Nelson et al. 2017), the geographic variation may also be influenced by the limited availability of local collaborators, support from national government agencies and ease of logistical arrangements, as observed in other Small Island Developing States (SIDS) (Hind et al. 2015; Kaiser-Bunbury et al. 2015; Weeks and Adams 2018). As others have highlighted (Levy 2008; Mendez et al. 2007), enabling Caribbean-based university-level education is a critical step towards developing self-sustaining research programmes in the region.

\section{Conservation implications and prioritising the way forward}

That the proportion of conservation publications in the literature did not increase over the study period is alarming and contrasts with the increasing focus on conservation in ornithology in the wider Neotropics (Freile et al. 2014) and globally (Bautista and Pantoja 2000), as well as in the wider ecological research (Lawler et al. 2006; Cronin et al. 2014). The failure to parallel this global and Neotropical trend could be a symptom of a broader deficiency in conservation-relevant research in the Caribbean (e.g. Donaldson et al. 2016), although conservation research effort was higher in threatened species than those with low extinction risk. However, the general lack of data for the majority of nonthreatened species is of concern. It is increasingly recognised that common species can undergo rapid declines, yet there continues to be complacency about the need to monitor such species (Inger et al. 2015; Lindenmayer et al. 2011). Indeed, over 50\% of Caribbean forest-dependent endemic species of least concern are experiencing population declines or have an unknown trend (IUCN 2017) and given our review, we risk failing to understand the factors limiting their populations.

Given the paucity of data for many Caribbean forest-dependent endemic species, the prioritisation of data collection for both threatened and non-threatened species becomes a key management question. While there is no substitute for long-term monitoring (Lindenmayer et al. 2012) and there are great examples of single-species population trend estimates 
in the Caribbean (e.g. Faaborg et al. 1997; Rusk 2017) that are invaluable to conservation managers, these remain the exception, not the norm. For example, although Hispaniola was overrepresented in this review, studies suggest that population trend data are lacking for resident endemic species on the island (Lloyd et al. 2016), illustrating that high research effort does not necessarily result in the data needed to manage or monitor species. Globally, gaps in conservation research are particularly apparent when research reflects personal or funding body interests, rather than focused attempts to gain management-relevant data (Lawler et al. 2006). If we are to successfully conserve forest-dependent bird species such as those in the Caribbean, managers require relevant and achievable data collection objectives, as proxies for long-term data such as population trends. In this context, future research on Caribbean forest endemics should include comparative demographic studies, models of population limitation, reproductive success, habitat requirements and re-analysis of existing data, as recommended for migratory birds (Faaborg et al. 2010). This would advance our understanding of species responses to environmental change, arguably the most pressing issue facing species conservation in the Caribbean, given the growing threat of climate change and impacts of increasing human populations for forest habitats (Williams 2013; Wunderle 2008).

The capacity for ornithological research in the Caribbean remains low (Levy 2008; Raffaele 2004), yet the Caribbean has a strong amateur and NGO ornithological community (Wardle et al. 2004), which with appropriate support can make a valuable contribution to building capacity and long-term monitoring. In this context, abundance data is an effective means of monitoring long-term trends, such as that gathered globally by eBird and the Christmas Bird Count (Sullivan et al. 2009), which can also facilitate revising species distributions to assess vulnerability (Lloyd et al. 2016). Replicating existing successful monitoring programmes, such as the Caribbean Waterbird Census (www.birdscaribbean. org), by tailoring survey methods specifically to forest habitats (Anderson et al. 2015; e.g. Gale et al. 2009) should be a priority for forest-dependent birds. Of great importance is the emphasis on promoting constant effort and widening geographic coverage of these organised counts in the Caribbean, as well as ensuring meaningful analysis of the resultant datasets. Greater collaboration is recommended between academics and practitioners, who often collect valuable ecological data but do not have the time or capacity for analysis. Facilitation of such collaborations could be led by regional conservation NGOs. Finally, primary literature is just one measure of research effort. Many local print, non-digital or non-English publications not cited on WoS, as well as grey literature will contain valuable data (e.g. Mugica et al. 2012) and are a means of bridging the practitioner-researcher gap (Gossa et al. 2015). Future work should focus on cost-effectiveness of research and promoting dialogue and partnerships between conservation professionals and researchers.

\section{Conclusion}

Birds are a taxon globally recognised as well-studied. Yet, while research on Caribbean endemic forest-dependent birds shows some encouraging trends of geographic and subject strengths, this review identifies important gaps and priority areas. These knowledge gaps are pertinent given the continued threats to these island birds (Wunderle 2008) and the importance of the region for forest-dependent bird conservation (Buchanan et al. 2011). While we can achieve a great deal of conservation with our current understanding, prioritising future research efforts based on this review will no doubt have wider implications 
for evidence-based conservation. Finally, the issues surrounding the inherent biases in research effort and their reciprocal effects on threat status and management of island species are relevant to all SIDS. Islands systems support a disproportionately large number of endemic and threatened species and, are of evolutionary significance, yet research efforts in SIDS face disproportionate challenges due to their human and economic development conditions. We recommend responsible collaboration among practitioners, and local and international researchers in order to inform a meaningful research agenda for these island species.

Acknowledgements We thank the University of Chester's Conservation Biology Research Group, the Birds Caribbean Endemic and Threatened Species Working Group, F. Rivera-Milan and J. Wunderle for insightful discussions. Thanks to A. von Hardenberg for advice on phylogenetic analysis and to the University of Chester High Performance Computing cluster. We are grateful to the anonymous reviewers whose comments on this and an earlier draft greatly improved this manuscript.

Open Access This article is distributed under the terms of the Creative Commons Attribution 4.0 International License (http://creativecommons.org/licenses/by/4.0/), which permits unrestricted use, distribution, and reproduction in any medium, provided you give appropriate credit to the original author(s) and the source, provide a link to the Creative Commons license, and indicate if changes were made.

\section{References}

American Ornithologists' Union [AOU] (1998) Checklist of North American Birds, 7th edn. American Ornithologists' Union, Washington, D.C.

Anderson AS, Marques TA, Shoo LP, Williams SE (2015) Detectability in audio-visual surveys of tropical rainforest birds: the influence of species, weather and habitat characteristics. PLoS ONE 10:e0128464

Arregoitia LDV, Blomberg SP, Fisher DO (2013) Phylogenetic correlates of extinction risk in mammals: species in older lineages are not at greater risk. Proc R Soc Lond B 280:20131092

Bambini L, Daley JR, Fenton C, Gray GA, James G, Martin L, Mendes S, Oppel S (2017) Current population status of four endemic Caribbean forest birds in Montserrat. J Caribb Ornithol 30:2-9

Bautista LM, Pantoja JC (2000) A bibliometric review of the recent literature in ornithology. Ardeola 47:109-121

Bellard C, Leclerc C, Courchamp F (2014) Impact of sea level rise on the 10 insular biodiversity hotspots. Glob Ecol Biogeogr 23:203-212

Bennett PM (1986) Comparative studies of morphology, life history and ecology among birds. University of Sussex

Bird JP, Buchanan GM, Lees AC, Clay RP, Develey PF, Yépez I, Butchart SH (2012) Integrating spatially explicit habitat projections into extinction risk assessments: a reassessment of Amazonian avifauna incorporating projected deforestation. Divers Distrib 18:273-281

Birdlife International (2016) BirdLife Data Zone. Birdlife International. http://www.birdlife.org/datazone. Accessed 20 Jan 2016

BirdsCaribbean (2019) BirdsCaribbean. http://www.birdscaribbean.org. Accessed 11 Feb 2019

Bregman TP, Sekercioglu CH, Tobias JA (2014) Global patterns and predictors of bird species responses to forest fragmentation: implications for ecosystem function and conservation. Biol Conserv 169:372-383

Brooke ZM, Bielby J, Nambiar K, Carbone C (2014) Correlates of research effort in Carnivores: body size, range size and diet matter. PLoS ONE 9:e93195. https://doi.org/10.1371/journal.pone.0093195

Brooks TM, Mittermeier RA, Mittermeier CG, Da Fonseca GA, Rylands AB, Konstant WR, Flick P, Pilgrim J, Oldfield S, Magin G (2002) Habitat loss and extinction in the hotspots of biodiversity. Conserv Biol 16:909-923

Brooks TM, Collar N, Green R, Marsden S, Pain D (2008) The science of bird conservation. Bird Conserv Int 18:S2-S12

Buchanan GM, Donald PF, Butchart SH (2011) Identifying priority areas for conservation: a global assessment for forest-dependent birds. PLoS ONE 6:e29080 
Carmel Y, Kent R, Bar-Massada A, Blank L, Liberzon J, Nezer O, Sapir G, Federman R (2013) Trends in ecological research during the last three decades-a systematic review. PLoS ONE 8:e59813

Carrara E, Arroyo-Rodríguez V, Vega-Rivera JH, Schondube JE, de Freitas SM, Fahrig L (2015) Impact of landscape composition and configuration on forest specialist and generalist bird species in the fragmented Lacandona rainforest, Mexico. Biol Conserv 184:117-126

Castro G, Locker I, Russell V, Cornwell L, Fajer E (2000) Mapping conservation investments: an assessment of biodiversity funding in Latin America and the Caribbean. Biodiversity Support Program, Washington, DC

Chaves A, Clozato C, Lacerda D, Sari E, Santos F (2008) Molecular taxonomy of Brazilian tyrant-flycatchers (Passeriformes: tyrannidae). Mol Ecol Resour 8:1169-1177

Clark JA, May RM (2002) Taxonomic bias in conservation research. Science 297:191-192

Conde DA, Flesness N, Colchero F, Jones OR, Scheuerlein A (2011) An emerging role of zoos to conserve biodiversity. Science 331:1390-1391

Cornell (2016) Cornell Neotropical Birds Database. http://neotropical.birds.cornell.edu/portal/species. Accessed 14 Jan 2016

Cronin DT, Owens JR, Choi H, Hromada S, Malhotra R, Roser F, Bergl R (2014) Where has all our research gone? a 20-year assessment of the peer-reviewed wildlife conservation literature. Int J Comp Psychol 27:101-116

Csardi MG (2013) Package ‘igraph’. Last accessed 3, 2013

Davis H (2017) Forest disturbance has negative consequences for the persistence of Jamaica's threatened and endangered bird species in Cockpit Country. J Caribb Ornithol 30:57-68

de Lima RF, Bird JP, Barlow J (2011) Research effort allocation and the conservation of restricted-range island bird species. Biol Conserv 144:627-632

de Villemereuil P, Nakagawa S (2014) General quantitative genetic methods for comparative biology. Modern phylogenetic comparative methods and their application in evolutionary biology. Springer, Berlin, pp 287-303

Deikumah JP, McAlpine CA, Maron M (2015) Matrix intensification affects body and physiological condition of tropical forest-dependent passerines. PLoS ONE 10:e0128521

del Hoyo J, Elliott A, Sargatal J, Christie DA, de Juana E (eds) (2016) Handbook of the birds of the world alive. Lynx Edicions, Barcelona

DeSalle R, Amato G (2004) The expansion of conservation genetics. Nat Rev Genet 5:702-712

Devenish-Nelson ES, Weidemann DE, Townsend JM, Nelson HP (2017) The role of a regional journal as a depository for valuable ornithological data as demonstrated by Caribbean forest endemic birds. J Caribb Ornithol 30:75-87

Diamond A (1973) Habitats and feeding stations of St Lucia forest birds. Ibis 115:313-329

Donaldson MR, Burnett NJ, Braun DC, Suski CD, Hinch SG, Cooke SJ, Kerr JT (2016) Taxonomic bias and international biodiversity conservation research. Canadian Science, Ottawa, ON

Ducatez S, Lefebvre L (2014) Patterns of research effort in birds. PLoS ONE 9:e89955

Duncan R, Blackburn T (2007) Causes of extinction in island birds. Anim Conserv 10:149-150

Dunning JB (1992) CRC handbook of avian body masses. CRC Press, BocaRaton

Epskamp S, Cramer AO, Waldorp LJ, Schmittmann VD, Borsboom D (2012) qgraph: network visualizations of relationships in psychometric data. J Stat Soft 48:1-18

Faaborg J, Dugger KM, Arendt WJ, Woodworth BL, Baltz ME (1997) Population declines of the Puerto Rican vireo in Guánica forest. Wilson Bull 109:195-202

Faaborg J, Holmes RT, Anders AD, Bildstein KL, Dugger KM, Gauthreaux SA, Heglund P, Hobson KA, Jahn AE, Johnson DH (2010) Conserving migratory land birds in the new world: do we know enough? Ecol Appl 20:398-418

Fordham DA, Brook BW (2010) Why tropical island endemics are acutely susceptible to global change. Biodivers Conserv 19:329-342

Frankham R (1998) Inbreeding and extinction: island populations. Conserv Biol 12:665-675

Freile JF, Greeney HF, Bonaccorso E (2014) Current neotropical ornithology: research progress 1996-2011. Condor 116:84-96

Gale GA, Round PD, Pierce AJ, Nimnuan S, Pattanavibool A, Brockelman WY (2009) A field test of distance sampling methods for a tropical forest bird community. Auk 126:439-448

Gillespie TW, Lipkin B, Sullivan L, Benowitz DR, Pau S, Keppel G (2012) The rarest and least protected forests in biodiversity hotspots. Biodivers Conserv 21:3597-3611

Gossa C, Fisher M, Milner-Gulland E (2015) The research-implementation gap: how practitioners and researchers from developing countries perceive the role of peer-reviewed literature in conservation science. Oryx 49:80-87 
Hadfield JD (2010) MCMC methods for multi-response generalized linear mixed models: the MCMCglmm R package. J Stat Soft 33:1-22

Hedges SB (2001) Biogeography of the West Indies an overview. Biogeography of the West Indies patterns and perspectives. CRC Press, Boca Raton

Hind EJ, Alexander SM, Green SJ, Kritzer JP, Sweet MJ, Johnson AE, Amargós FP, Smith NS, Peterson AM (2015) Fostering effective international collaboration for marine science in small island states. Front Mar Sci 2:86

Holdschlag A, Ratter BMW (2013) Multiscale system dynamics of humans and nature in The Bahamas: perturbation, knowledge, panarchy and resilience. Sustain Sci 8:407-421

Hughes JM (1996) Phylogenetic analysis of the Cuculidae (Aves, Cuculiformes) using behavioral and ecological characters. Auk 113:10-22

Inger R, Gregory R, Duffy JP, Stott I, Vořřšek P, Gaston KJ (2015) Common European birds are declining rapidly while less abundant species' numbers are rising. Ecol Lett 18:28-36

IUCN (2017) The IUCN Red List of Threatened Species. Version 2016. http://www.iucnredlist.org. Accessed June 2017

IUCN (2018) The IUCN Red List of Threatened Species. Version 2018-2

Jetz W, Thomas G, Joy J, Hartmann K, Mooers A (2012) The global diversity of birds in space and time. Nature 491:444-448

Johnson T, Stattersfield A (1990) A global review of island endemic birds. Ibis 132:167-180

Johnson MD, Kellermann JL, Stercho AM (2010) Pest reduction services by birds in shade and sun coffee in Jamaica. Anim Conserv 13:140-147. https://doi.org/10.1111/j.1469-1795.2009.00310.x

Julliard R, Jiguet F, Couvet D (2004) Common birds facing global changes: what makes a species at risk? Glob Change Biol 10:148-154

Kaiser-Bunbury CN, Fleischer-Dogley F, Dogley D, Bunbury N (2015) Scientists' responsibilities towards evidence-based conservation in a Small Island Developing State. J Appl Ecol 52:7-11. https://doi. org/10.1111/1365-2664.12346

Latta SC (2012) Avian research in the Caribbean: past contributions and current priorities. J Field Ornithol $83: 107-121$

Latta SC, Faaborg J (2009) Benefits of studies of overwintering birds for understanding resident bird ecology and promoting development of conservation capacity. Conserv Biol 23:286-293

Lawler JJ, Aukema JE, Grant JB, Halpern BS, Kareiva P, Nelson CR, Ohleth K, Olden JD, Schlaepfer MA, Silliman BR (2006) Conservation science: a 20-year report card. Front Ecol Environ 4:473-480

Levy C (2008) History of ornithology in the Caribbean. Ornitol Neotrop 19:415-426

Lewis T, Simmons L (2010) Creating research culture in Caribbean universities. Int J Educ Dev 30:337-344

Lindenmayer D, Wood J, McBurney L, MacGregor C, Youngentob K, Banks S (2011) How to make a common species rare: a case against conservation complacency. Biol Conserv 144:1663-1672

Lindenmayer DB, Likens GE, Andersen A, Bowman D, Bull CM, Burns E, Dickman CR, Hoffmann AA, Keith DA, Liddell MJ (2012) Value of long-term ecological studies. Austral Ecol 37:745-757

Lloyd JD, Rimmer CC, McFarland KP (2016) Assessing conservation status of resident and migrant birds on Hispaniola with mist-netting. PeerJ 3:e1541

Lugo AE, Schmidt R, Brown S (1981) Tropical forests in the Caribbean. Ambio 10:318-324

Lugo AE, Carlo TA, Wunderle JM Jr (2012a) Natural mixing of species: novel plant-animal communities on Caribbean Islands. Anim Conserv 15:233-241

Lugo AE, Helmer EH, Santiago Valentín E (2012b) Caribbean landscapes and their biodiversity. Interciencia 37:705-710

Manne LL, Pimm SL (2001) Beyond eight forms of rarity: which species are threatened and which will be next? Animal conservation forum, vol 3. Cambridge University Press, Cambridge, pp 221-229

Marsden SJ, Royle K (2015) Abundance and abundance change in the world's parrots. Ibis 157:219-229

McKenzie AJ, Robertson PA (2015) Which species are we researching and why? a case study of the ecology of British breeding birds. PLoS ONE 10:e0131004

Mendez M, Gómez A, Bynum N, Medellín R, Porzecanski AL, Sterling E (2007) Availability of formal academic programs in conservation biology in Latin America. Conserv Biol 21:1399-1403

Miller LD, Miller JY (2001) The biogeography of West Indian butterflies (Lepidoptera: Papilionoidea, Hesperioidea): a vicariance model. In: Woods CA, Sergile FE (eds) Biogeography of the West Indies: patterns and perspectives. CRC Press, Boca Raton, pp 229-262

Mortensen JL, Reed JM (2016) Population viability and vital rate sensitivity of an endangered Avian cooperative breeder, the white-breasted thrasher (Ramphocinclus brachyurus). PLoS ONE 11:e0148928

Mugica L, Acosta M, Jiménez A, Rodríguez A (2012) Current knowledge and conservation of Cuban waterbirds and their habitats. J Caribb Ornithol 25:64-76 
Murray H, Green E, Williams D, Burfield I, Brooke MdL (2015) Is research effort associated with the conservation status of European bird species? Endanger Species Res 27:193-206

Myhrvold NP, Baldridge E, Chan B, Sivam D, Freeman DL, Ernest S (2015) An amniote life-history database to perform comparative analyses with birds, mammals, and reptiles. Ecology 96:3109

Nelson HP, Townsend JM, Weidemann DE, Proctor CJ (2017) Status of Caribbean forest endemics special issue: editors foreword. J Caribb Ornithol 30:1

Newbold T, Scharlemann JP, Butchart SH, Şekercioğlu ÇH, Alkemade R, Booth H, Purves DW (2013) Ecological traits affect the response of tropical forest bird species to land-use intensity. Proc R Soc Lond B 280:20122131

Onyefulu CC, Ogunrinade A (2005) Kick-starting research in newly emergent universities: why faculty do not apply for research development 'seed' funding at the University of Technology, Jamaica. J Res Adm 36:14

Oppel S, Cassini A, Fenton C, Daley J, Gray G (2014a) Population status and trend of the critically endangered Montserrat Oriole. Bird Conserv Int 24:252-261

Oppel S, Hilton G, Ratcliffe N, Fenton C, Daley J, Gray G, Vickery J, Gibbons D (2014b) Assessing population viability while accounting for demographic and environmental uncertainty. Ecology 95:1809-1818

Orgaz A, López G (2015) Potential of birdwatching tourism in the Caribbean: an analysis of Dominican Republic. PASOS: Revista de Turismo y Patrimonio Cult 13:43-55

Paradis E, Claude J, Strimmer K (2004) APE: analyses of phylogenetics and evolution in R language. Bioinformatics 20:289-290

Plummer M, Best N, Cowles K, Vines K (2006) CODA: convergence diagnosis and output analysis for MCMC. R news 6:7-11

Portillo-Quintero CA, Sánchez-Azofeifa GA (2010) Extent and conservation of tropical dry forests in the Americas. Biol Conserv 143:144-155. https://doi.org/10.1016/j.biocon.2009.09.020

Purvis A, Cardillo M, Grenyer R, Collen B (2005) Correlates of extinction risk: phylogeny, biology, threat and scale. In: Purvis A, Gittleman JL, Brooks T (eds) Phylogeny and conservation. Cambridge University Press, Cambridge, pp 295-316

Raffaele HA (2004) The challenge for future research and conservation efforts in the Caribbean. J Caribb Ornithol 17:159-160

Raffaele H, Wiley J, Garrido O, Keith A, Raffaele J (2003) Birds of the West Indies. Christopher Helm, London

Rimmer CC, Johnson PL, Lloyd JD (2017) Home range size and nocturnal roost locations of Western Chat-Tanagers (Calyptophilus tertius). Wilson J Ornithol 129:611-615

Roberts BE, Harris WE, Hilton GM, Marsden SJ (2016) Taxonomic and geographic bias in conservation biology research: a systematic review of wildfowl demography studies. PLoS ONE 11:e0153908

Rusk BL (2017) Long-term population monitoring of the critically endangered Grenada Dove (Leptotila wellsi) on Grenada, West Indies. J Caribb Ornithol 30:49-56

Ryder OA, Feistner AT (1995) Research in zoos: a growth area in conservation. Biodivers Conserv 4:671-677

Şekercioğlu CH, Schneider SH, Fay JP, Loarie SR (2008) Climate change, elevational range shifts, and bird extinctions. Conserv Biol 22:140-150

Sullivan BL, Wood CL, Iliff MJ, Bonney RE, Fink D, Kelling S (2009) eBird: a citizen-based bird observation network in the biological sciences. Biol Conserv 142:2282-2292

Sutherland WJ, Pullin AS, Dolman PM, Knight TM (2004) The need for evidence-based conservation. Trends Ecol Evol 19:305-308

Thompson W (2013) Sampling rare or elusive species: concepts, designs, and techniques for estimating population parameters. Island Press, New York

Tossas AG (2004) Ornithological research and conservation efforts in Puerto Rico. J Caribb Ornithol 17:67-71

Tossas AG, Delannoy CA (2001) Status, abundance, and distribution of birds of Maricao state forest, Puerto Rico. El Pitirre 14:47-53

Townsend JM, Rimmer CC, Driscoll CT, McFarland KP, Inigo-Elias E (2013) Mercury concentrations in tropical resident and migrant songbirds on Hispaniola. Ecotoxicology 22:86-93

Townsend JM, Rimmer CC, Latta SC, Meijia D, Garrido E, McFarland KP (2018) Nesting ecology and nesting success of resident and endemic tropical birds in the Dominican Republic. Wilson J Ornithol 130:849-858

Verde Arregoitia LD (2016) Biases, gaps, and opportunities in mammalian extinction risk research. Mammal Rev 46:17-29 
Wardle C, Wallace K, Gape L (2004) The role of non-professional in Caribbean and Bermudan ornithology. J Caribb Ornithol 17:155-158

Weeks R, Adams V (2018) Research priorities for conservation and natural resource management in Oceania's small island developing states. Conserv Biol 32:72-83

Wege D, Anadon-Irizarry V (2005) Towards a globally threatened bird program for the Caribbean. J Caribb Ornithol 18:88-93

White RL, Bennett PM (2015) Elevational distribution and extinction risk in birds. PLoS ONE 10:e0121849

Wiley JW, Wunderle JM (1993) The effects of hurricanes on birds, with special reference to Caribbean islands. Bird Conserv Int 3:319-349

Wiley JW, Gnam RS, Koenig SE, Dornelly A, Galvez X, Bradley PE, White T, Zamore M, Reillo PR, Anthony D (2004) Status and conservation of the family Psittacidae in the West Indies. J Caribb Ornithol 17:94-154

Williams JN (2013) Humans and biodiversity: population and demographic trends in the hotspots. Popul Environ 34:510-523

Wunderle JM (2008) From the past to the globalized future for Caribbean birds. J Caribb Ornithol 21:69

Wunderle J Jr, Arendt W (2017) The plight of migrant birds wintering in the Caribbean: rainfall effects in the annual cycle. Forests 8:115

Publisher's Note Springer Nature remains neutral with regard to jurisdictional claims in published maps and institutional affiliations.

\section{Affiliations}

\section{Eleanor S. Devenish-Nelson ${ }^{1,2}$ (D) Douglas Weidemann ${ }^{3} \cdot$ Jason Townsend $^{4}$. Howard P. Nelson ${ }^{1}$}

1 Department of Biological Sciences, University of Chester, Parkgate Road, Chester CH1 4BJ, UK

2 Department of Biomedical Sciences, University of Edinburgh, Teviot Place, Edinburgh EH8 9AG, UK

3 BirdsCaribbean, 4201 Wilson Blvd. Suite 110-174, Arlington, VA 22203, USA

4 Biology Department, Hamilton College, Clinton, NY 13323, USA 